\title{
Correction to: A single-dose indomethacin prophylaxis for reducing perinatal brain injury in extremely low birth weight infants: a non- inferiority analysis
}

\author{
Ramachandra Bhat $^{1} \cdot$ Michael Zayek $^{1} \cdot$ Paul Maertens $^{2} \cdot$ Fabien Eyal $^{1}$
}

Published online: 31 October 2019

(c) The Author(s), under exclusive licence to Springer Nature America, Inc. 2019

\section{Correction to: Journal of Perinatology}

https://doi.org/10.1038/s41372-019-0509-4

published online 30 September 2019

Since online publication of this article, the authors noticed that the legend for Figure 1 contains an error. The correct legend is provided below.

Calculated (hypothetical) pharmacokinetic model depicting plasma levels of indomethacin during first postnatal week in an extremely low birth weight infant exposed to different prophylactic dosing regimens. (Using the weight of the infant as $500 \mathrm{~g}$, indomethacin plasma levels were calculated applying following equations (Supplementary text): (1) Plasma concentration initial $=\operatorname{dose}(\mathrm{mg}) /$ volume of distribution (L). (2) Volume of distribution of indomethacin $=0.28 \times$ weight $(\mathrm{kg})+0.0041 \times$ postnatal age in days (Weist et al. [15]). (3) Plasma concentration subsequent $=$ plasma concentration initial $\times \mathrm{e}^{-\mathrm{kt}}, \mathrm{k}=0.69$ / half-life, $\mathrm{t}=$ subsequent time in hours; indomethacin halflife $=94 \mathrm{~h}$ (Smith et al. [12]).
Ramachandra Bhat

rbhat@health.southalabama.edu

1 Department of Pediatrics, Division of Neonatology, University of South Alabama, Mobile, AL, USA

2 Department of Neurology, Child Neurology Division, University of South Alabama, Mobile, AL, USA 